\title{
Roadshow Coaching Of "Ceria" Application To Improve Teacher Collaboration In Improving Learning Services In Early Childhood Education
}

\author{
$1^{\text {st }}$ Lenni Arta F S Sinaga ${ }^{1}, 2^{\text {nd }}$ Wesley Hutabarat $^{2}, 3^{\text {rd }}$ Yuniarto Mudjisusatyo $^{3}$ \\ \{lenniarta2013@gmail.com $\left.{ }^{1}\right\}$ \\ Student of Doctoral Study Program-Educational Management ${ }^{1}$, Lecturer of Doctoral \\ Study Program-Educational Management ${ }^{2,3}$ \\ Universitas Negeri Medan
}

\begin{abstract}
Early childhood education (ECE) is critical for children's growth and development. Thus, ECE teachers as the spearhead of ECE implementation must constantly improve ECE services. As a result of ICT, many applications have emerged, including ECE services. For example, the CERIA program was created to help ECE teachers collaborate online and in person to improve ECE learning. Tech developments will not help teachers if they cannot use the application optimally. As a result, roadshow instruction is required to enable ECE teachers use "CERIA." Moreover, pre-activity interviews with ECE teachers revealed that teachers needed innovation to support online and offline collaboration. Thus, a coaching roadshow to numerous ECE instructors in Medan was required to achieve teacher collaboration in improving ECE learning using the researchers' developed "CERIA" application. It is established from the results of implementation that this coaching roadshow can improve teacher collaboration from planning through performance and follow-up.
\end{abstract}

Keywords: Ceria application, ECE, roadshow coaching.

\section{Introduction}

Educators are at the forefront of achieving learning objectives in the implementation of early childhood education and one of the determining factors for the quality of ECE because most ECE quality indicators are related to the duties of ECE teachers. ECE teachers must constantly improve their competence so that ECE services can be continuously improved, especially in the implementation of the teaching and learning process.

The professional development of teachers is effectively enhanced when the teacher team has been encouraged to become a learning community [1]. Peer coaching is a professional development model for teachers through mutual observation, discussion, and good practices. Based on the results of statements that have been made, ECE teachers already have a culture of debate among fellow teachers to plan to learn for the next meeting. However, observing each other, sharing good practices, and giving each additional strengthening learning have not been familiarized by ECE teachers.

Zepeda (2013) [2][3] stated that peer coaching model consisting of preparation, observation, and preobservation. The peer coaching model in this study was designed and strengthened, and adapted to the characteristics of ECE with the name "CERIA," which is an 
acronym for C: Content Focus, E: Effective Observation, R: Reflective Collaboration, I: Inspirational

Feedback and A: Active to Improve and to Reinforce. "CERIA" as a peer coaching resulting from the development can be implemented in learning by combining face-to-face mechanisms or utilizing the "CERIA" mobile application.

For the "CERIA" peer coaching model to be applied to ECE units, it is necessary to carry out Road Show Coaching, namely by conducting socialization and direct assistance to the target ECE units in turn. Therefore, road Show coaching was carried out in 10 ECE units in the city of Medan. In the coaching roadshow activities, teachers were directly mentored to apply the CERIA application to collaborate to improve competence.

Roadshow coaching the application CERIA applications for ECE teachers in Medan city aims to increase teacher collaboration in increasing competition and improving the quality of learning in ECE. Through the CERIA application, ECE teachers apply peer coaching from learning reflection, implementing peer observation, collaborative review, providing inspiring feedback, and making learning improvements consistently and continuously.

\section{Method}

Application implementation is carried out using the roadshow coaching method, namely by providing direct assistance and turns to each predetermined target. The stages of the activities carried out are:

a. Coordination with ECE units that have been set as targets to agree on the schedule and strategy for implementing "CERIA" peer coaching

b. "CERIA" peer coaching online socialization and distribution of peer coaching implementation guidelines

c. Form a WhatsApp group per ECE unit as a means of communication with all ECE unit heads and the peer coaching team Tim

d. Assist each ECE directly and alternately

e. Accompanying teachers in implementing the CERIA cycle according to the ongoing learning theme

f. Accompanying the Head of the ECE Unit in monitoring the implementation of CERIA's Peer Coaching.

\section{Result and Discussion}

\subsection{Socialization of CERIA peer coaching to 10 (ten) ECE Units in the City of Medan}

This All ECE units that were targeted gave a positive response and realized real support, namely:

a. Establish a peer coaching team consisting of experienced teachers with new, excellent teachers with adequate or adequate teachers with difficulties

b. Monitor the implementation of the CERIA model stages

c. Evaluate the achievement of peer coaching every cycle. 


\subsection{The formation of Ten peer coaching teams spread over Ten ECE units}

The Peer Coaching Team that the head of the ECE unit has appointed after being assisted has been able to implement a series of CERIA peer cycles with the following processes:

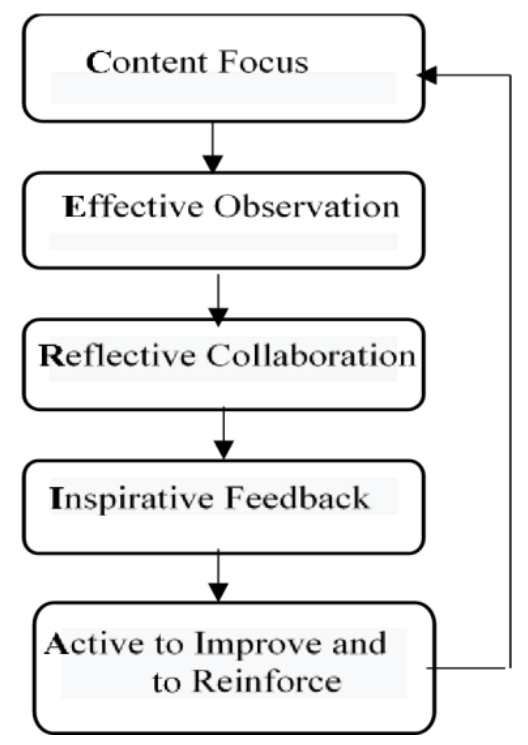

Fig. 1. The "CERIA" peer coaching cycle.

3.2.1 Content Focus. The coachee teacher sets the focus of the teacher's reflection every day after the learning process is complete. Daily review is carried out by re-evaluating and analyzing the learning process carried out to conclude that the focus is on what works and what doesn't work. The process continues with critical thinking about how these practices and actions can be more effective. The reflection process can also be done by recalling or using recordings [4]. Not only "coachee" teachers, teachers who act as "coach" also do their reflection every day. The 'coach' teacher is open to supporting the 'coachee' teacher when asked, agreeing on an observation schedule according to the focus to be observed. The 'coachee' teacher is also preparing to receive class visits conducted by the 'coach' teacher. The "coach" teacher continues to carry out the learning process, as usual, does not change the learning significantly because the observation process carried out by the 'coach' teacher does not aim to assess the 'coachee' teacher.

3.2.2 Effective Observation. After the content that is the focus is known based on the results of daily reflections, then the Coach Teacher conducts practical observation activities by observing videos/documentation sent by the coachee teacher. At this stage, the teacher 'coach' takes an accurate picture of the implementation of learning without conducting an evaluation. The Coach teacher makes observations effectively by noting the potentials of the 'coachee' teacher as material for reflection collaboration. Statements were made by observing the videos/ recordings/ documentation of the Coache teacher while carrying 
out the learning process in the classroom, virtual, online. This phase is in line with Eri's research (2014). In addition, coaches record videos of aspects of teaching behavior that they want to improve, meet with colleagues, view and discuss videos focusing on solutions. This phase is in line with the research of [5]. Teachers' benefit by engaging in different types of observations at other times is that they gain gradual benefits over some time by being part of a dynamic community of practice [6]. The head of ECE has also facilitated a peer coaching program by scheduling observations or organizing activities during the peer observation period [7].

3.2.3 Reflective Collaboration. Doing reflective collaboration on the results of observations (Reflective Collaboration). The coach and coachee teachers reflect on the recorded observations. The coachee teacher responds to the 'coach' teacher's questions and exploring the coachee teacher's strengths in learning. The 'coach' teacher and the coachee teacher build a shared understanding of effective practice, discuss and reflect on aspects of agreed learning practices as the focus of observation. Discussions were conducted based on observational evidence, oriented to the impact of learning strategies on student development, non-judgmental, emotional, and superficial but exploring each other's strengths. Discussions are also carried out by prioritizing close cooperation and focusing their efforts on common goals. Therefore, they must have the same thoughts. The 'coach' teacher develops teacher 'coachee' resources through questioning, challenging, and supportive skills. Collaborative reflection on the results of direct observations or through video recordings of teaching is also done by asking questions - online peer coaching by utilizing WhatsApp. Responding to teacher needs, sharing, and inspiring habits highlight the strengths of teachers encouraging each teacher to be able to formulate opportunities for learning improvement.

3.2.4 Provide inspiring feedback. The teacher conveys feedback to fellow teachers who are inspiring, not teaching, and is designed to encourage teachers to highlight their potential to improve the learning process. The essence of inspiring feedback is a focus on professional development. The coachee teacher responds to the inspirational input given by the 'coach' teacher by reading and studying the examples shared by the 'coach' teacher with the same content, then trying to formulate their solutions. After the teacher is inspired, the process is continued by designing solutions to improve the Daily Learning Program Plan which will be applied to the next lesson. Feedback is descriptive and evidence-based, helps improve teaching, is given as soon as possible. Teachers provide each other with the opportunity to exchange ideas, opinions, and good practices, encourage each other to think more deeply about their teaching practices, share knowledge, get used to sharing their own experiences or portfolios with people. Feedback is more significant because the coaching teacher gives answers according to the teacher's needs. The habit of sharing and inspiring each other highlights the strengths of teachers, encouraging each teacher to formulate opportunities for learning improvement

3.2.5 Active to Improve and to Reinforce. Actively take corrective and strengthening actions (Active to Improve and to Reinforce) The coachee teacher is active in improving the learning process following the revised RPPH. The remediation activities are documented to get reinforcement from fellow teachers or ECE heads. The implementation of new strategies, improving teaching and learning in Peer Coaching is 
carried out continuously in a cycle and changes content according to the needs and agreement of the teacher. The results of this study are in line with research by Jarvis et al. (2017), who concluded that to improve the competence of ECE teachers, peer coaching is necessary because it can create a culture of professionalism and continuous improvement. The concept of "coaching" in "peer coaching" is a strategy of continuous professional improvement and is embedded in the work of a teacher [8], [9], creates a culture of improvement in schools (Dellapenna, 2017), and provide support for the teacher community trying to master new skills [10], [11], Peer coaching offers teachers opportunities: to self-reflection, share classroom experiences, and experience shared growth in teaching [6] [12] [13], observe each other, share good practices to improve their teaching performance (Koça, 2016 ), encourage teacher professional growth based on teaching practices, teacher learning, teamwork, and teacher confidence, enthusiasm, and autonomy [14] and based on teacher strengths (Haberlin, 2019) and as one of the most effective forms of the beginning of learning embedded in work [15], even for students, school leaders and educational institutions [15].

\subsection{Increased Collaboration in Improving Competence And Improving The Quality Of Learning}

The results of interviews with teachers indicate an increase in collaboration that affects the improvement of competence and improvement of quality of learning. The collaboration process by helping each other learn between fellow teachers can also be done through online learning. Through the stages of determining focus and daily reflection will make teachers think about their teaching. Using an instrument that has been designed, the teacher will be able to recall which ones have been achieved and which have not. Teachers like it because it makes them pay attention to what students are doing and learning. Give ideas or focus to the teacher about small things to change. When fellow teachers observe the lessons that other teachers will do, they will force themselves and think more carefully about what they are teaching. They want to do well on what their co-teachers choose to observe, so they take more time than usual to plan the learning themes on which the learning focuses. The teacher will still do it because there is no reason not to do it. Teachers think that when they are in the teaching and learning process, sometimes they can't see all of the children's reactions to what they have done or follow, so teachers are happy when fellow teachers are willing to observe the learning process they can work together. Teachers are interested because they get perspective from fellow teachers, helps them to see teaching from a new perspective, motivates us to improve each other's learning.

The teachers stated that the CERIA Peer coaching model helped in this COVID-19 pandemic situation because they had to do online learning. CERIA's peer coaching provides new awareness for teachers to learn to improve their competencies constantly. In addition, opportunities between teachers are very open to learn from each other and work together through the CERIA Peer coaching process. CERIA's peer coaching has also been proven to reduce stress because discussions are held between fellow teachers to increase teaching effectiveness. Through CERIA peer Coaching, teachers are more confident and enthusiastic about improving learning. 


\section{Conclusion}

Roadshow coaching activities for implementing the CERIA application have been carried out for $10 \mathrm{ECE}$ units in the city of Medan. From the coaching roadshow activity, ten peer coaching teams have been formed that apply the CERIA cycle, and teachers collaborate to improve the competence of ECE teachers in improving learning. Collegiality and collaboration approaches have proven to be very important in enhancing the professional development of teachers. Because the application of CERIA Peer Coaching is still limited to 10 ECE units, it is hoped that further researchers can develop and disseminate it to a broader target.

Acknowledgement. For the first and foremost, the writer would like to express her deepest gratitude for Almighty God, for his marvelous so the writer has finally completed this paper also to my promotor and co promotor and for all the ECE teachers and head who participate ini this roadshow coaching.

\section{References}

[1] Chen CC. Facilitation of Teachers' Professional Development through Principals' Instructional Supervision and Teachers' Knowledge-Management Behaviors. 2018; 51

[2] Zepeda SJ, Ilgan, Parylo O. Peer coaching: Comparing the American and Turkish educators' willingness to adopt and implement peer coaching as a form of teacher professional development. 2013; 2(1): 64.

[3] Zepeda S J. The principal as instructional leader: A practical handbook. 3rd ed. New York: Larchmont NY Eye On Education; 2013.

[4] Julie. Reflective Practice and Supervision for Coaches. Maidenhead, UK; Open University Press; 2007. [pp 43-49] .

[5] Thurlings M, Vermeulen M, Bastiaens T, Stijnen S. The role of feedback and social presence in an online peer coac hing program for student teachers. 2014;30(3): 326.

[6] Nicolson M, Harper F. Online Peer Observation: An Exploration of a Cross-Discipline Observation Project. 2014; 26(2): 251.

[7] Yee LW. Peer Coaching for Improvement of Teaching and Learning Journal of Interdisciplinary Research in Education. 2016; 6(1): 64-70.

[8] DiBella DKS, Williams DKG, Glover DLC. Improving Pre-Service Teachers' Readiness to Integrate Technology with Cross-Curricular Adaptations. 2015; 4(2(1): 84.

[9] Morgan M, Rochford S. Coaching and Mentoring for Frontline Practitioners. Dublin: Centre for Effective Services; 2017. 1-21.

[10] Joyce BR, Showers B. Student achievement through staff development. 3rd Editon. Longman: Inc. Cover; 2002.

[11] Sinkinson C. An assessment of peer coaching to drive professional development and reflective teaching Communications in Information Literacy. 2011;5(1):9.

[12] Rhodes R. Supporting Novice Teachers: Peer Coaching and Collaborative Inquiry as Support. 2017.

[13] Gonen KI. A Study on Reflective Reciprocal Peer Coaching for Pre-service Teachers: Change in Reflectivity. 2016; 4(7): 211.

[14] Amal A, Alabdulhadib M, and Alrwaished N. Impact of peer coaching strategy on pre- service teachers' professional development growth in Kuwait International. 2017; 86: 36-49. 
[15] Soisangwarn A, Wongwanich S. Promoting the Reflective Teacher through Peer Coaching to Improve Teaching Skills. 2014; 116: 2504-2511.

[16] Devine M, Meyers R, Houssemand C. How can Coaching Make a Positive Impact Within Educational Settings?. 2013; 93: 1382-1389. 